\title{
Society conferences
}

\section{BOS}

The British Orthodontic Society (BOS)

Conference will be held in Glasgow at the

Scottish Event Campus (SEC) on 19-21

September 2019, and has just announced that acclaimed IVF pioneer and popular television presenter Professor Robert Winston (pictured) will be opening and speaking at the event.

Lord Winston is Professor of Science and Society and Emeritus Professor of Fertility Studies at Imperial College London. He is also Chairman of the Genesis Research Trust - a charity which raised over $£ 13$ million

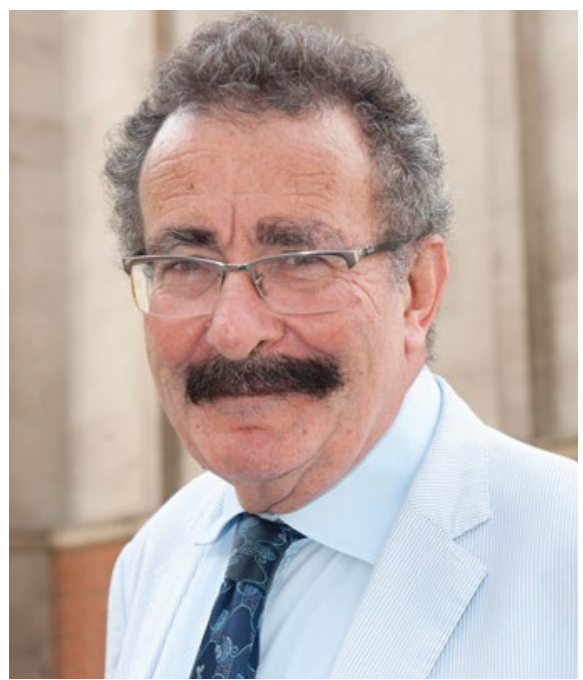

Lord Winston, Professor of Science and Society and Emeritus Professor of Fertility Studies at Imperial College London to establish the Institute of Reproductive and Developmental Biology and which now funds high quality research into women's health and babies.

The conference will offer a packed schedule including a pre-conference course on the Psychology of Orthodontics and Decision Making, two parallel sessions, a DCP programme and excellent social events including a gala reception and a conference ball with ceilidh dancing until late.

Registration is open at https://www.bos. org.uk/BOC-Glasgow-2019. An early bird discount is available before 30 June and a combined team rate is also available.

\section{BAOS}

The British Association of Oral Surgeons' (BAOS') Annual Conference will be held at the Mercure Bristol Grand Hotel on 25-27 September 2019.

Highlights of the conference programme include international speaker Professor Von Arx; updates from allied specialties including oral medicine, ophthalmology, orthodontics, periodontics and cardiology; sessions on sepsis, odontogenic cysts and tumours; and a careers breakout session to discuss national recruitment, pathways and options and how to get published.

Social evenings including sampling the local cheese and cider are planned.
For more information and to book, visit https://www.baos.org.uk/annual-conference-2019/. A dental nurses' study day is also being held at the conference on the Thursday.

\section{BSPD}

The British Society of Paediatric Dentistry (BSPD) will be holding its conference at Birmingham's Repertory Theatre on 11-13 September 2019.

With the theme 'Hearts and Minds', the conference will jointly focus on the holistic management of patients with cardiac conditions and how mental health can affect both patients and teams. The importance of collaboration and interdisciplinary working between paediatric dentists and medical teams will be evident throughout.

The winner of the BSPD's Outstanding Innovation Award will give a short talk. This year's winner, Helen Rogers, will present on her prize winning trainee-led research collaborative CONNECT Trainees.

Social events will include The Angel of the North Quiz which will be held at The Old Library and the Annual Conference Dinner which will be held at Fazeley Studios. Both are based in Digbeth, the cultural and creative hub of Birmingham.

Registration is open at https://bspdconference.org.uk/. Early bird rates are available until the end of July 2019.

\section{'Decay won't be solved with token efforts' say BDA}

The British Dental Association (BDA) has said that low attendance among under- 1 s at dental practices is indicative of failure from successive governments to offer a joined-up approach to the oral health of children in England.

A study from Birmingham University, published in Community Dental Health in February, found $3 \%$ of under-1s attended a dentist, but with significant local variation. In some areas like Worcestershire levels were as low as $1 \%{ }^{1}$

The BDA supports the idea of getting children to a dentist early, to encourage good habits and embed a preventative approach. It has however criticised the lack of ambition from authorities to deliver on this vision. The Association has called for a concerted and joined-up approach covering primary schools and nurseries, GPs, health visitors and other care providers.

Dentist leaders have characterised England as now receiving a 'second-class' service. Wales and Scotland both have dedicated national child oral health programmes, which operate outreach in schools and nurseries, including supervised brushing.

The Government's centrepiece policy Starting Well programme, aimed at improving oral health outcomes for 'high risk' children, has no new funding attached. Only around 300 practices out of almost 9,000 NHS practices in England are currently involved in the programme.

BDA Chair Mick Armstrong said: 'Tooth decay is the number one reason young children will end up in hospital, and it won't be solved with token efforts. Baby teeth matter, and getting very young kids attending requires joined-up action. Sadly ministers have offered little more than posters to pop up in dental practices.

'Preaching to the converted will not cut it. We need real engagement in schools and nurseries, and Scotland and Wales are already leading the way. Kids in England deserve better than a second-class service.'

\section{References}

1. Salomon-Ibarra C C, Ravaghi V, Hill K, Jones $C$ M, Landes D P, Morris A J. Low rates of dental attendance by the one of one and inequality between local government administrative areas in England. Community Dent Health 2019; 36: 22-26 